British Food Journal

Emerald

British Food Journal

Perceptions and experiences of early-adopting registered dietitians in integrating nutrigenomics into practice

\begin{tabular}{|r|l|}
\hline Journal: & British Food Journal \\
\hline Manuscript ID & BFJ-08-2017-0464.R1 \\
\hline Manuscript Type: & Research Paper \\
\hline Keywords: & $\begin{array}{l}\text { Nutrigenomics, Personalised Nutrition, Perceptions, Registered Dietitians, } \\
\text { Qualitative }\end{array}$ \\
\hline
\end{tabular}

SCHOLARONE ${ }^{\text {M }}$

Manuscripts 


\section{Perceptions and experiences of early-adopting registered dietitians in integrating nutrigenomics into practice}

Purpose - This research explores the perceptions and experiences of early adopters of the technology.

Design/Method/Approach - Registered Dietitians (RD's) (N=14) were recruited from the UK, Canada, South-Africa, Australia, Mexico and Israel. Six qualitative interviews and two focus groups were conducted online using a conference calling platform. Data were recorded, transcribed and thematically analysed.

Findings - Early adopters of Nutrigenomics (NGx) were experienced, self-efficacious RD's who actively sought knowledge of NGx through communication with one another and the broader scientific community. They considered NGx an extension of current practice and believed RD's had the skills to deliver it. Perceived barriers to widening the application of NGx were linked to skepticism among the wider dietetics community. Proliferation of unregulated websites offering tests and diets was considered 'pseudoscience' and detrimental to dietetics fully embracing NGx. Lack of a sustainable public health model for the delivery of NGx was also perceived to hinder progress. Results are discussed with reference to 'diffusion of innovation theory'.

Originality/Value - The views of RD's who practice NGx have not been previously studied. These data highlight requirements for future dietetic training provision and more inclusive service delivery models. Regulation of NGx services and formal recognition by professional bodies is needed to address the research/practice translation gap. Further research is required to enquire as to the views of the wider dietetics profession. 
Key words Nutrigenomics, Personalised Nutrition, Perceptions, Registered Dietitians, Qualitative.

Paper Type Research article.

\section{Introduction}

Nutritional genomics (NGx) is an emerging field focused on interactions between food, nutrition and genes (Ferguson et al., 2016). Increased understanding of gene-nutrient interactions may facilitate health and disease prevention (Casas et al., 2016; Corella et al., 2016; Celis-Morales et al., 2016). A growing market offers genetic tests "direct-toconsumer" as well as via healthcare professionals. The Food4me project has illustrated how personalized nutrition can be delivered online to the public (Celis-Morales et al., 2016). Tests can deliver information linking diet to health, lifestyle, weight or improved fitness (Covolo et al., 2015; Bloss et al., 2011). Omics technologies (metabolomics, lipidomics and transcriptomics) enable highly personalized and targeted approaches to dietary health promotion (Sun and $\mathrm{Hu}, 2016$ ) which have already been shown effective for outcomes related to cardiovascular disease (Fitó et al., 2016). Consumer interest is high and demand for trained practitioners expected to increase (Berezowska et al., 2015). Registered Dietitians (RD's) will be key professionals for translating the science of nutrigenomics into practice (Berezowska et al., 2015; Abrahams et al., 2017; Stewart-Knox et al., 2016; Fallaize et al., 2015; Stewart-Knox et al., 2013). The Academy of Nutrition and Dietetics (A.N.D), however, do not consider the field ready for routine practice (Camp and Trujillo, 2014), so that application of nutritional genomics has tended to be low amongst the dietetics profession (Collins et al., 2013; Whelan et al., 2008).

Whilst two large multinational European studies (LIPGENE and Food4me) have explored consumer perceptions of personalized nutrition (Stewart-Knox et al., 2016; 
Stewart-Knox et al., 2013; Poínhos et al., 2014; Stewart-Knox et al., 2009), and some research on stakeholder views has been undertaken (Ronteltap, 2008), to our knowledge no research has investigated perceptions and experiences of Registered Dietitians (RD's) who are already delivering personalized nutrition services (Abrahams et al., 2017). Rogers' (2003) diffusion of innovation theory describes a process by which an innovation disseminates through a societal group taking into account various adopter categories (early adopters; early majority; late majority; laggards), communication (awareness and knowledge of the innovation), innovation decision processes (initial knowledge; attitude; intention to adopt or reject; implementation; decision to adopt or reject) and characteristics of the technology (relative advantage; compatibility/fit; complexity/ease of use; trialability; observability of results). According to innovation theory, a novel technology such as nutritional genomics will diffuse through society via early adopters such as freelance RD's (Peterson et al., 2007). This study, therefore, has sought to understand the perceptions, experiences and characteristics of registered dietitians who have integrated genetic testing into practice. The objectives have been to determine the profile of an early-adopter RD, to explore perspectives among early adopters, to understand challenges encountered in integrating NGx in practice, capture views on the future role for RD's in the delivery of personalized nutrition and, to construct theory through which to understand and explain the above.

\section{Method}

\subsection{Sampling}

Volunteers were approached through the managing directors (CEO's) of three international Direct-to-Consumer (DTC) genetic testing companies working with registered dietitians (RD's). The aim was to sample from a range of countries 
(Australia; Canada; Israel; Mexico; South Africa; United Kingdom) and in doing so to obtain the various perspectives of RD's working alongside different health systems. An information sheet was sent via email to practicing RD's in their database. Inclusion criteria were English speaking RD's who had been applying nutrigenomic (NGx) testing in practice for at least 6 months. Of 20 invitations, 11 RD's (55\%) responded and agreed to participate (Table 1). No remuneration was offered.

\section{Insert table I here}

\subsection{Materials}

Interviews and focus groups were conducted using the Citrix Platform (Citrix Systems Inc). Topics discussed included: experience of using tests in practice; perceptions of NGx; perceived barriers, challenges and drivers; skills required; perceived implications for education and training; and, future directions. Open-ended questions included: "tell me about how you got started in the field"; "what has your experience been with using tests with your clients been so far?"; and "how do you think you are perceived by your dietetic colleagues?".

\subsection{Procedure}

Ethical approval was obtained from the University of Bradford Research Ethics Committee. Pilot interviews were conducted with two UK-based RD's. Given technical problems during the first interview, and that the second pilot interviewee appeared more relaxed and verbal without the camera, it was decided not to use video in the main study. Mixed methods were employed in order to achieve an international perspective. 
Where a focus group was not pragmatic because of time zone differences, individual interviews were conducted. This approach also enhanced the possibility of obtaining rich, novel data. Whereas group discussions by virtue of the social interaction, facilitate expression of new ideas (Kitzinger, 1994), interviews allow for the expression of diverse, more privately held views (Silverman, 2013). Once a date and time was agreed, dial-in details to access the conference calling facility were sent via email. One final email reminder was sent a day before the call. On the day of the interview, participants accessed the online conference room. Discussion was moderated by the first author (MA). A total of 6 interviews and 2 focus groups were held between February and April 2016 ranging between 30-60 minutes in length, at which point data were deemed saturated.

\subsection{Data Analysis}

Anonymised transcripts were transcribed from the recordings verbatim by MA. Thematic analysis was deemed appropriate as this was an under-researched topic and group (Vaismoradi et al., 2013). All transcripts were read and re-read recursively by the first author (MA). Data were encoded using an inductive approach and then explored and organized into themes that were inclusive of the data set and common to all transcripts. Initial themes were checked, refined and categorized further into subthemes. To assure rigor, consistency and reliability of the coding and analysis, a second author (BS-K) checked the transcripts against the coding framework and themes. Any discrepancies were discussed and themes and sub-themes agreed, interpreted and pertinent extracts selected. 


\section{Results and Discussion}

Data were best described by 4 main themes (profile of the NGx practitioner; experiences of RDs in practice; perceived barriers to $\mathrm{NGx}$; and, perspectives on the future and sub-themes (Figure 1). These provide insights into NG practice from the perspective of practicing RD's, and convey their opinions and views on how clinical practice and training could and should evolve, and how best to deliver such services in the future.

\section{Insert figure 1 here}

\subsection{Profile of the NGx Practitioner}

Nutrigenomics RD's were highly trained and experienced (Table 1), and were selfemployed within private practice, or working in a clinic employed by a General Practitioner (GP) for clients who were self-insured or had their own companies.

\section{Agency/Self-Efficacy: Acquiring the Skill-Base}

The RD's had actively sought and engaged in activities associated with continuous professional development, which enabled them to learn more about NGx. Becoming part of the wider scientific culture was considered key to keeping up with the rapid scientific advance associated with NGx, and crucial to best practice. Consistent with diffusion theory (Rogers, 2003), adoption of nutrigenomics was perceived to be driven by the RD's themselves through collaboration and communication with one another and between the technology and users. Participants spoke of attendance at scientific conferences that were not exclusively dietetic which provided opportunities to network, 
actively seek out new knowledge and share it with interested professionals both within and beyond dietetics.

Okay, so what happened is that I went to an Expo in the United States ... that was the first time I really knew about nutrigenomics ... this was five years ago. Then I started to study a bit more ... reading by ourselves" (FG1, Mexico)

This sense of agency appeared to be underpinned by interests beyond dietetics (eg. sports science; complementary medicine) which widened their knowledge, skill set and worldview.

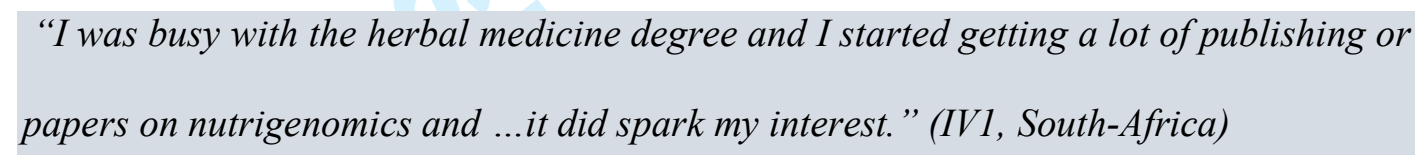

\section{Agency/Self-Efficacy: Applying Existing Skills}

The RD's claimed to possess a wide skill-set which reached into various ancillary fields rendering them competitive in the nutrigenomics marketplace. They reported being able to apply existing skills and acquire new ones. Diffusion theory holds that innovation decision processes such as initial knowledge are important for adoption (Rogers, 2003). The consensus was that RD's already possessed the skills required to deliver personalized nutrition, such as counselling clients 'one to one' and translating information into practical solutions (eg. menus). NGx was considered merely an add-on to the range of tools already at the disposal of the RD.

\footnotetext{
"... at the end of the day we are giving menus and we are all doing the same kind of approach with the patients of giving one on one visits and everything. I think what makes us different it is that we use a DNA test." (FG1, Mexico)
} 
Whilst nutrigenomic practice was new, there was agreement that RD's were in effect already providing such advice, and required no new skills apart from a basic understanding of genetics.

"I'm not sure that you need any different skills because the skill has always been to translate the person's medical or social or other issues into something practical that they can use to improve their nutrition." (IV5, Australia)

Perceived skills already held also included 'passion' for the science and having the 'self-confidence' to apply and deliver it.

"Passion for the subject, I think, is the main skill." (IV6, South-Africa)

"It's just the only skill they need is self-confidence - that they are qualified to do it." (IV4, Australia)

These findings are consistent with those of previous quantitative research that found skills and experience were associated with pre-adoption of novel technologies among health professionals (Aarons et al., 2011). Whilst previous research on RDs has suggested that integration of NGx into practice may be commercially driven through the sale of tests (Cormier et al., 2014; Li et al., 2014), drivers included their keen interest in technology, 'love' for the subject and desire to add value to what they offered their clients.

\subsection{Experiences of NGx in Practice: Becoming Empowered and Engaged}

Our participants conveyed positive experiences of applying NGx in practice and noted how it excites and motivates clients and brings about compliance with personalised advice. 
“... when it is personalized, you know that it is based on your genes, and you really get this sense from people like they're interested in it, they're excited, they understand what changes they need to make...... it's very motivational" (FG2, Canada)

This aligns with previous research which found that personalised information improved healthy eating indices (Celis-Morales et al., 2016) and adherence to a Mediterraneantype dietary pattern (Livingstone et al., 2016). Diffusion theory holds that aspects of the technology such as observability of results, is important for its adoption (Ronteltap et al., 2007). Using nutrigenomic testing with clients was perceived by the RD's to enhance their confidence, render them more engaged as therapists and enable “different” practice.

"Because I have more confidence in the exact recommendations I'm giving them. I might actually be counseling differently - for whether they had a nutrigenomics test or not." (FG2, Canada)

Confidence in using the new technology mirrors existing survey studies which indicated that lack of confidence was associated with low involvement in NGx (Collins et al., 2013; Oosthuizen, 2011; Whelan et al., 2008). Whether this was a response to personalized recommendations, or the style of delivery, is unclear. That the RD's felt more engaged when a client had undergone NGx testing could explain dietary change in their clients. It is generally accepted that healthcare professionals play an integral role in bringing about behaviour change in consumers (Rankin et al., 2016; Solas et al., 2016). As 'diffusion of innovation' theory would suggest (Peterson et al., 2007; Rogers, 2003), the RD's appear to be 'champions' of the technology and acting as 'agents' in its application. Further research is required to unravel the effect of the messenger (practitioner) from the message (genotype) and the technology applied. 


\subsection{Perceived Barriers to Integration of NGx into Dietetics Practice}

Challenges faced by RD's in integrating NGx technology into practice related to social norms associated with the professional context of practice, the perceived researchtranslation-practice gap and the need for regulation and practice guidelines.

\section{Perspectives on the wider Dietetics and Medical Professions}

Diffusion theory postulates that attitude toward and acceptance of new technologies is the result of a trade-off between the perceived cost/risk and benefit of doing so (Ronteltap et al., 2008). Where risk is perceived, especially where knowledge is considered limited, as is the case with nutrigenomics, there can be uncertainty about the potential benefit of the technology. Participants in the current study reported differences between RD's in private and public practice in their tolerance of risk and uncertainty which were perceived to limit application of nutrigenomics. It was felt that there was little recognition of NGx by the wider scientific and medical community who were perceived as risk averse and lacking a sense of adventure rendering them unresponsive to emerging science affecting nutrition. This apparent 'us and them' view of dietetics practice may reflect a perceived differing culture between RD's who worked in independent private practice as opposed to those employed in public health services. This implies some dissociation between early adopters of NGx and the wider dietetics profession. Terms such as "conservative", "fear", "scary", "lack of awareness", “confused", "less flexible" and 'reluctance' were used when referring to the wider profession.

\footnotetext{
"Overall I think the dietetic professionals tend to be a little bit...... less adventurous in terms of finding out what works for a patient. They're less flexible." (IV1, South-Africa)
} 
There was awareness of misperceptions widely held among peers of what NGx comprises, as well as a narrow view of what falls within the scope of dietetic practice. Nutrigenomic testing (focused around personalizing diets for health), tended to be confused with disease risk prediction and reduction, (associated with disease outcomes and therefore not considered within dietitians' scope of practice).

\begin{abstract}
“And then some people just really not knowing what it's about at all, ...or thinking that it's too much about predicting disease, which it's not. And I think there's a lot of confusion. Education is huge here." (FG2, Canada)
\end{abstract}

Perceived negativity toward NGx was also attributed to skepticism among the wider profession about the efficacy of novel technologies. This perspective fits with diffusion theory which holds that characteristics of the technology pertinent to adoption are likely to be related to its perceived efficacy (Ronteltap et al., 2007).
"The response has always been, "well, that's not something that we necessarily learned." and "how scientifically proven is it?" (IV6, South-Africa)

There was consensus that despite enough evidence for the efficacy of NGx at this time, disinterest prevailed among the wider profession.

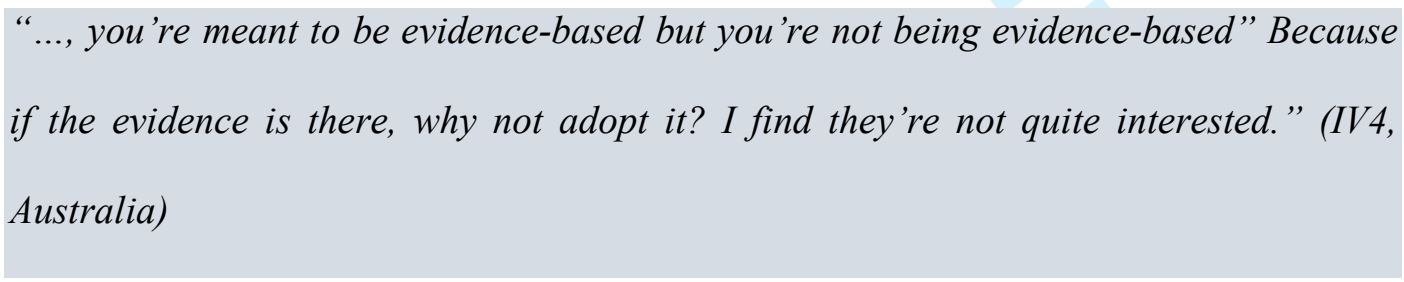

As diffusion theory (Rogers, 2007) would imply, there was a concensus that communication was needed to address misperceptions of the science among the wider profession. Meanwhile, there was awareness that acceptance of nutrigenomics among peers was growing and that attitudes were gradually becoming more positive. 


\begin{abstract}
"So, when I first started out, the perception was incredibly poor ... "that's a bit of a dodgy space, isn't it?")...Ass times moved on, acceptance or the realization that actually, this is an area, an actual area of science, and it's important for nutrition as a whole ... that perception has definitely grown." (IV3, Australia)

\section{Science versus Pseudoscience}

Whilst it was accepted that the science of NGx was (at the time of data collection) developing, it was agreed that there was sufficient current evidence to make actionable recommendations. Perceptions of risk and uncertainty are important for the acceptance or rejection of new food technologies (Ronteltap et al., 2007). The perception of an innovation as low risk has previously been shown to increase pre-adoption of novel technology in allied health professions (Mitchell et al., 2010; Greenhalgh et al., 2004). NGx was considered low risk because it is entirely evidence based and targeted towards the promotion of health rather than disease risk reduction.

\footnotetext{
"We're just trying to make a diet more precise according to your DNA. We're not taking on the whole, you know preventing major illnesses." (FG2, Canada)
}

There was a consensus that the wider dietetics profession considered NGx as 'pseudoscience', thus was restricting application in practice. This echoes previous research indicating that $\mathrm{NGx}$ is not considered relevant to the practice of clinical dietetics ( $\mathrm{Li}$ et al., 2014; Christianson et al., 2005). Participants felt that they were competing in a marketplace awash with unregulated and diverse offerings, some based on weak or non-existent science and prescribed 'fad diets' delivered by less-qualified nutrition practitioners often promoted by celebrities.

"I think we're facing a huge challenge in the social media space where anyone who's a celebrity can say "Look at me this is the diet I follow. Isn't this fantastic?" You know 
the most ridiculous people promoting the most ridiculous diets and people believe them over traditional dietitians or science, true science." (IV5, Australia)

Proliferation of unregulated niche commercial offerings was perceived to have fueled skepticism toward nutrigenomics among the dietetics profession and was blamed for lack of recognition among the wider scientific community.

"I think there's a lot of skepticism, is this yet another fad? And there are companies that are doing really obscure stuffs in all sorts of areas." (IV5, Australia)

There was a perceived need for clearer practice guidelines to enable consistent use of genomics terminology, especially across countries.

"What I find challenging is the lack of guidelines of best practice out there because the results they're not "one-size-fit-all”. They still depend on the context of it - the health context of the patient themselves. I mean, the environment plays such a large role." (IV3, Australia)

The International Society of Nutrigenomics and Nutrigenetics recently published guideline papers to ensure that the field is communicated scientifically and accurately (Ferguson et al., 2016; Kohlmeier et al., 2016).

\section{Research-Knowledge-Translation Gap}

A perceived gap between the body of research knowledge and how to apply it was considered a contributing factor to the lack of translation of NGx into practice.

\footnotetext{
"But what I find lacking is the translation into practice or the interventions - what to actually do about it." (IV3, Australia)
}

There was the view that the only way to learn about NGx and for personalised nutritional science to advance, research and practice should be integrated as far as 
possible. This notion of 'research in practice' could be a function of the autonomy that working in private practice affords practitioners.

“Someone's gotta jump first, right? Cause you won't have evidence until people are jumping. It's like you can't expect there to be enough evidence if people aren't using it. " (IV4, Australia)

Consistent with the notion of innovation diffusing through a community by means of 'champions' (Rogers, 2007), a future was envisioned in which they, as leaders in the field, would play a crucial role in ensuring that translational research is conducted by RD's, helping to build the evidence-base.

\subsection{Preparing for the Future}

Diffusion theory (Rogers, 2007) emphasises communication between stakeholders in the adoption of innovation. Accordingly, sub-themes on the future of NGx related to training and education, application in practice and the need for new models of service provision.

\section{Education}

Teaching of nutritional genomics at undergraduate level, with courses delivered by those with practical experience in the field, was considered crucial to ensure that the translational aspect was included during clinical placements (Wright, 2014). This view is consistent with recent calls for a more integrative and functional approach to the dietetic curriculum (Augustine et al., 2016). Incorporation of novel technology into curricula has been positively associated with adoption of new innovations among various professions (Aarons et al., 2011; Mitchell et al., 2010; Greenhalgh et al., 2004). Participants believed that nutritional genomics should be part of the undergraduate core 
curriculum, delivered by experts with experience in the field. A concern was that dietetics' could be 'left behind' as the science advances.

"If they keep being behind, one day it will be a lot of studying to do ... in 5 years or even a year later, if you want to get into nutrigenomics there's been more and more information. And the barrier would be that yes you have to study." (FG1, Mexico)

There were also concerns that not enough emphasis was placed on the relevance of nutritional genomics to dietetics practice, which could be more extensively covered in the curriculum.

"You know, if you think of the - four years that we study, it's kind of like mentioned in
passing in one of the lectures. And, because it's not part of the standard teaching ... the
fresh ones just out of varsity, think that it is irrelevant."(IV1, South-Africa)

Lack of exposure to NGx in undergraduate education was considered a threat to translating the science or practice in a safe environment before graduation. The current curriculum was viewed as requiring integration of newer scientific advancements which overlap with nutrigenomics (e,g, metabolomics and metagenomics). Internships were suggested as potential solutions to bridging the research/practice gap.

"Yeah, I would agree that this is the future of dietetics. I feel like it's going to be the younger generation that really picks up on it. And I do see it becoming a more common component of the curriculum at the undergraduate level and having it more into internships and things like that." (FG2, Canada)

\section{Models for Delivering Personalised NGx Services}

Another important insight was that, following initial contact with clients to explain the genetic results and provide nutritional recommendations, discussants preferred to hand 
over long-term counselling to another RD who specialised in dietary behaviour change. An ideal model was one that embraced a team approach whereby clients/patients would first be seen by a 'systems' RD who would go through their genetic, metabolic and other profiles using a precision nutrition approach. This would be followed by a counselling RD who would help them to make the recommended dietary changes.

"Or nearly, when the nutrigenomics dieticians work with other more traditional
dieticians, when they come in and they do that consult and then the other dietician takes
over. That would be a better model."(IV4, Australia)

This approach would fit with the proposed business models outlined in the Food4me White Paper (Food4me, 2015) and with diffusion theory (Peterson, 2007), whereby RD's act as "connectors" for other health professionals. Hubs of practitioners would then interpret results, translate the science and provide support to other healthcare professionals who would communicate personalized dietary advice (online or otherwise). Although the viability of this model would need assessment, it could fit well within public health care systems and commercial services (Stewart-Knox et al., 2016).

\section{Limitations of the Commercial Model}

There was some discomfort about dietetics becoming integral to commercial offerings in that it may cater mainly for the wealthy, worried, well (Fischer et al., 2016), and could exclude economically disadvantaged clients and that this could deter adoption among practitioners working in the public health sector. Consistent with previous research on potential consumers of NGx (Stewart-Knox et al., 2016), discussants referred to growing concern around health inequalities and the imperative for the benefits of precision nutrition approaches to reach those who need it the most. 


\begin{abstract}
"And then, if anyone affiliated with the company, perhaps? There's that-it's seen as a bit of a conflict of interest, mistrust because we know a lot of, you know, industry partnerships have turned out badly. And I think the public and professionals, including dieticians, are very hesitant about things that are seen to be, you know commercialized." (FG2, Canada)
\end{abstract}

It was anticipated that national healthcare systems would play an important role in the provision of personalized nutrition services (Stewart-Knox et al., 2016; Fallaize et al., 2015). In the UK, for example, health services are free at the point of contact, clients will expect NGx to be provided free of charge.

\title{
Optimism
}

Nutrigenomics was seen as a positive force in dietetics and one that (by definition) is tightly evidenced-based. Adding nutrigenomics services to an offering had potential to keep dietetics 'relevant', while slow uptake of NGx was considered detrimental to the profession's credibility in the field.

\footnotetext{
"We have to be so evidence-based and anything in the periphery, you're gonna lose as far as your credibility and your reputation...." (FG2, Canada)
}

Despite the perceived lack of support from dietetics peers and wider health professionals, the RD's remained determined and optimistic, another key trait of early adopters (Wisdom et al., 2014).
“It's definitely not one of those fads or trends. Um it's just booming ... and think it's going to be huge, a huge thing in the future" (FG2, Canada)

All participants were either self-employed or working in the private sector, where practitioners had autonomy to use NGx. Early adoption of the technology, therefore, 
was unsurprising in view of the 'diffusion of innovation theory' whereby those with greater control to create change, are more likely to adopt innovation (Peterson et al., 2007; Rogers, 2003; Backer et al., 1986). This could potentially explain the low application of NGx in public health organisations (Collins et al., 2013; Whelan et al., 2008) where strategic decisions regarding practice would be centrally managed. Whereas innovation can diffuse 'bottom-up' from champions at the practice end (Peterson et al., 2007), top-down leadership can be negatively associated with adoption of new technologies (Backer et al., 1986). This suggests that for NGx to become mainstream new models for innovation management may need to be considered.

\section{Conclusions}

This research has sought insight into the experiences and perspectives of RD's who have taken the leap and ventured into NGx practice. Early adopters of NGx were experienced, self-efficacious RD's who actively sought knowledge of NGx through communication at conferences and other media. By virtue of being in the private sector they had autonomy and were able to apply their new knowledge in practice. NGx was considered an extension of current practice for which RD's already had the skills. Perceived skepticism among peers about the efficacy of NGx was perceived to deter adoption of NGx and was blamed on the unregulated proliferation of websites offering tests and 'fad' diets. Reluctance to adopt nutrigenomics among the wider dietetics community was also attributed to concern about the potential to widen health inequality by catering to the worried well to the neglect of sustainable public health models for delivery of services to the wider population (Fischer et al., 2016). None of the RDs practiced across national borders so worked along-side national health care provision which apparently varied in the level of service offered. Interviewees in the UK and 
Israel referred to how NGx testing seemed far removed from national health care provision, which focussed on treatment of acute chronic diseases to the neglect of health promotion and prevention. In Australia and South-Africa, in contrast, private medical insurance in some cases allows earned reward points to be used to purchase NGx tests so that no 'out of pocket' spend is required. In the Canadian focus group, one participant mentioned how their healthcare system allowed individuals could buy a test privately and be later reimbursed for the dietetic consultation.

Themes fitted well with diffusion of innovation theory (Rogers, 2003). Ronteltap and colleagues (2007) extended diffusion theory and proposed that acceptance of nutrigenomics will depend upon not only risk and uncertainty, communication and characteristics of the technology, but also the degree of perceived control the user may have over the test results and the subjective norm. By virtue of being independent practitioners, the RD's in our study would have sufficient autonomy (perceived control) to translate nutrigenomic results into prescribed behaviour and thereby diffuse the technology 'bottom up'. The subjective norm (what others are perceived to be doing) in this case among the wider dietetics profession, was one of 'lacking adventure' and of being managed 'top-down', effectively constraining the ability of RD's to introduce novel technologies into practice. Adoption of nutrigenomics, therefore, may depend upon whether the user is in private or public practice.

Previous qualitative research involving stakeholders implied that adoption of nutrigenomics could rely upon effective commercial exploitation (Ronteltap et al., 2008). This study, therefore, is appropriate, timely and novel in providing a window into the perceptions and experiences of NGx derived from the accounts of practicing RD's. Although this study has taken an international perspective, as with all qualitative research, results are not generalizable to the general dietetic population and may require 
testing by quantitative means. Another limitation was that because data were gathered online without video, there was no way to gauge non-verbal communication. Owing to time zone differences, some participants were interviewed individually whilst others were part of a focus group. Whereas focus group discussion could have been influenced by groupthink causing discussion to reach consensus and limiting the diversity of opinion expressed (Silverman, 2013), Interview may have enabled individuals to express their personal experiences, opinions and feelings (Fielding, 1994). Combining focus group with individual interviews will have reduced any such biases on data quality (Lambert and Loiselle, 2016). No cross-national differences were observed in approach to the topic. It was clear that adoption of NGx was strongly linked to interest in the field irrespective of country. Those who were more experienced in the field, however, tended to be more vocal in the focus groups. In the Mexican focus group, the leading practice and training $\mathrm{RD}$ was more vocal and appeared more comfortable in expressing her thoughts in English. This was managed by the interviewer who ensured that all participants had an opportunity to speak and that a range of opinions were voiced. There was the possibility that sending the invitation to participate through the company CEO could have inhibited discussion of matters specific to the commercial sector. That RD's in our sample all worked in private practice, may have biased responses. Reflecting the controversial nature of the topic, some of the quotes could be perceived as provocative. The perceived views of those working in public services, for example, were referred to at length, implying a need for future research to better understand the views of those RD's working in various public health-care systems. Another bias was that all participants were female. Whilst males make up a smaller percentage of the dietetics profession, they may have a different perspective and are worthy of study. That the researcher is a practicing NGx RD and known to some 
interviewees could have affected the dynamic and influenced responses. Any bias in data analysis, however, was minimized through the inclusion of a second analysist who was not an RD. As data saturation was reached with 12 participants from 6 different countries, it is unlikely that further novel insight could have been found by including more participants.

Our findings have implications for dietetic practice and health policy. Regulation was a concern for the practitioners and one that has previously identified among consumers (Fischer et al., 2016). Whilst it may be easy for RD's to identify reputable companies, guidance may be required for new professionals entering the field (Backer et al., 1986). Perceived negativity among the dietetics profession could also be addressed through tighter regulation of the industry and formal recognition by professional bodies. Actions are required to link teaching, research and practice to address the translation gap. As part of their professional development, for example, established dietitians could attend scientific conferences enabling networking and exchange of ideas with the wider scientific community. RD's should also be encouraged to apply existing skills to new approaches to therapy. Meanwhile, to address health inequalities, more inclusive models for the delivery of NGx will be required. As the prospect of a precision health-care era becomes increasingly likely in the short term, RD's will be key to the successful application of emerging novel nutritional technologies. Further research is required in order to better understand the modifiable traits and skills of early adopters within group which can be instilled among the next generation of practitioners to future-proof the profession.

\section{Acknowledgement}


The authors wish to convey their sincere gratitude to the dietitians who so generously gave their time to take part in this research.

\section{References}

Aarons, G.A., Hurlburt, M. and Horwitz, S.M. (2011), “Advancing a conceptual model of evidence-based practice implementation in public service sectors", Administration and Policy in Mental Health, Vol.38, pp.4-23.

Abrahams, M., Frewer, L. and Stewart-Knox, B. (2017), Factors determining the integration of nutritional genomics into clinical practice by registered dietitians, Trends in Food Science and Technology, Vol.59, pp.139-147.

Augustine, M.B., Swift, K.M., Harris, S.R., Anderson, E. J. and Hand, R.K. (2016), Integrative medicine: education, perceived knowledge, attitudes and practice among Academy of Nutrition and Dietetics members. Journal of the Academy of Nutrition and Dietetics, Vol.116, pp.319-29.

Backer, T.E., Liberman, R.P. and Kuehnel, T.G. (1986), Dissemination and adoption of innovative psychosocial interventions. Journal of Consulting and Clinical Psychology, Vol.54, pp.111-8.

Berezowska, A., Fischer, A.R., Ronteltap, A., van der Lans, I.A. and van Trijp, H.C. (2015), Consumer adoption of personalised nutrition services from the perspective of a risk-benefit trade-off. Genes and Nutrition, Vol.10, pp.42.

Bloss, C.S., Darst, B.F., Topol, E.J. and Schork, N.J. (2011), Direct-to-consumer personalized genomic testing. Human Molecular Genetics, Vol.20, pp.132-41. 
Camp, K.M. and Trujillo, E. (2014), Position of the Academy of Nutrition and Dietetics: nutritional genomics. Journal of the Academy of Nutrition and Dietetics, Vol.114, pp.299-312.

Casas, R., Sacanella, E., Urpí-Sardà, M., Corella, D., Castañer, O., Lamuela-Raventos, R.M., Salas-Salvadó, J., Martínez-González, M.A., Ros, E. and Estruch, R. (2016), Long-term immunomodulatory effects of a Mediterranean diet in adults at high risk of cardiovascular disease in the PREvención con DIeta MEDiterránea (PREDIMED) Randomized Controlled Trial. Journal of Nutrition, Vol.146, pp.1684-93.

Celis-Morales, C., Livingstone, K.M., Marsaux, C.F., Macready, A.L., Fallaize, R., O'Donovan, C.B., Woolhead, C., Forster, H., Walsh, M.C., Navas-Carretero, S., San-Cristobal, R., Tsirigoti, L., Lambrinou, C.P., Mavrogianni, C., Moschonis, G., Kolossa, S., Hallmann, J., Godlewska, M., Surwiłło, A., Traczyk, I., Drevon, C.A., Bouwman, J., van Ommen, B., Grimaldi, K., Parnell, L.D., Matthews, J. N., Manios, Y., Daniel, H., Martinez, J.A., Lovegrove, J.A., Gibney, E.R., Brennan, L., Saris, W.H., Gibney, M., Mathers, J.C. and Study, F.M. (2016), Effect of personalized nutrition on health-related behaviour change: evidence from the Food4me European randomized controlled trial. International Journal of Epidemiology, pii: dyw186. [Epub ahead of print] PMID: 27524815

Christianson, C.A., McWalter, K.M. and Warren, N.S. (2005), Assessment of allied health graduates' preparation to integrate genetic knowledge and skills into clinical practice. Journal of Allied Health, Vol.34, pp.138-44.

Collins, J., Bertrand, B., Hayes, V., Li, S.X., Thomas, J., Truby, H. and Whelan, K. (2013), The application of genetics and nutritional genomics in practice: an 
international survey of knowledge, involvement and confidence among dietitians in the US, Australia and the UK. Genes and Nutrition, Vol.8, pp.523-33.

Corella, D., Asensio, E.M., Coltell, O., Sorlí, J.V., Estruch, R., Martínez-González, M., Salas-Salvadó, J., Castañer, O., Arós, F., Lapetra, J., Serra-Majem, L., GómezGracia, E., Ortega-Azorín, C., Fiol, M., Espino, J. D., Díaz-López, A., Fitó, M., Ros, E. and Ordovás, J.M. (2016), CLOCK gene variation is associated with incidence of type-2 diabetes and cardiovascular diseases in type-2 diabetic subjects: dietary modulation in the PREDIMED randomized trial. Cardiovasular Diabetology, Vol.15, pp.4.

Cormier, H., Tremblay, B.L., Paradis, A.M., Garneau, V., Desroches, S., Robitaille, J. and Vohl, M.C. (2014), Nutrigenomics - perspectives from registered dietitians: a report from the Quebec-wide e-consultation on nutrigenomics among registered dietitians. Journal of Human Nutrition and Dietetics, Vol.27, pp.391400.

Covolo, L., Rubinelli, S., Ceretti, E. and Gelatti, U. (2015), Internet-based direct-toconsumer genetic testing: A systematic review. Journal of Medical Internet Research, Vol.17, e.279.

Fallaize, R., Macready, A.L., Butler, L.T., Ellis, J.A., Berezowska, A., Fischer, A.R., Walsh, M.C., Gallagher, C., Stewart-Knox, B.J., Kuznesof, S., Frewer, L.J., Gibney, M.J. and Lovegrove, J.A. (2015), The perceived impact of the National Health Service on personalised nutrition service delivery among the UK public. British Journal of Nutrition, Vol.13, pp.1271-9.

Ferguson, L.R., de Caterina, R. and Gorman, U. (2016), Guide and position of the International Society of Nutrigenetics/Nutrigenomics on personalised nutrition: 
Part 1 - Fields of Precision Nutrition. Journal of Nutrigenetics and Nutrigenomics, Vol.9, pp.12-27.

Fielding, N. (1994), Varieties of research interviews. Nurse Research, Vol.1, pp.413.Fischer, A.R., Berezowska, A., van der Lans, I.A., Ronteltap, A., Rankin, A., Kuznesof, S., Poínhos, R., Stewart-Knox, B., and Frewer, L.J. (2016), Willingness to pay for personalised nutrition across Europe. The European Journal of Public Health, Vol.26, pp.640-644.

Fitó, M., Melander, O., Martínez, J.A., Toledo, E., Carpéné, C. and Corella, D. (2016), Advances in integrating traditional and omic biomarkers when analyzing the effects of the Mediterranean diet intervention in cardiovascular prevention. International Journal of Molecular Science, Vol.17, pp.1469.

Food4me. (2015), Personalised nutrition: paving a way to better population health. A White Paper from the Food4me Project. European Food Information Council (EUFIC) (eds): Belgium.

Greenhalgh, T., Robert, G. and Macfarlane, F. (2004), Diffusion of innovations in service organizations: systematic review and recommendations. Milbank Quarterly, Vol.82, pp.581-629.

Kitzinger, J. (1994), The methodology of focus groups: the importance of interaction between research participants. Sociology of Health and Illness, Vol.16, pp.103121.

Kohlmeier, M., de Caterina, R., Ferguson, L.R., Görman, U., Allayee, H., Prasad, C., Kang, J.X., Nicoletti, C.F. and Martinez, J.A. (2016), Guide and position of the International Society of Nutrigenetics/Nutrigenomics on personalized nutrition: 
Part 2 - Ethics, challenges and endeavors of precision nutrition. Journal of Nutrigenetics and Nutrigenomics, Vol.9, pp.28-46.

Lambert, S.D. and Loiselle, C.G. (2008), Combining individual interviews and focus groups to enhance data richness. Journal of Advanced Nursing, Vol.62, pp.22837.

Li, S.X., Collins, J. and Lawson, S. (2014), A preliminary qualitative exploration of dietitians' engagement with genetics and nutritional genomics: perspectives from international leaders. Journal of Allied Health, Vol.43, pp.221-8.

Livingstone, K.M., Celis-Morales, C., Navas-Carretero, S., San-Cristobal, R., Macready, A.L., Fallaize, R., Forster, H., Woolhead, C., O'Donovan, C.B., Marsaux, C.F., Kolossa, S., Tsirigoti, L., Lambrinou, C.P., Moschonis, G., Godlewska, M., Surwiłło, A., Drevon, C.A., Manios, Y., Traczyk, I., Gibney, E.R., Brennan, L., Walsh, M.C., Lovegrove, J.A., Saris, W.H., Daniel, H., Gibney, M., Martinez, J.A., Mathers, J.C. and Study, F.M. (2016), Effect of an internet-based, personalized nutrition randomized trial on dietary changes associated with the Mediterranean diet: the Food4Me Study. American Journal of Clinical Nutrition, Vol.104, pp.288-97.

Mitchell, S.A., Fisher, C.A. and Hastings, C.E. (2010), A thematic analysis of theoretical models for translational science in nursing: mapping the field. Nursing Outlook, Vol.58, pp.287.

NHS Department of Health (2014), Five Year Forward Review. Available at https://www.england.nhs.uk/ourwork/futurenhs/nhs-five-year-forward-viewweb-version/5yfv-exec-sum/ (accessed 1.11.2016) 
Oosthuizen, L. (2011), Aspects of the involvement, confidence, and knowledge of South-African registered dietitians regarding genetics and nutritional genomics. MSc Thesis (MNutr) at University of Stellenbosch (South Africa). Available at http://scholar.sun.ac.za/handle/10019.1/6796 Downloaded on 15.10.2015

Peterson, J.C., Rogers, E.M., Cunningham-Sabo, L. and Davis, S.M. (2007), A framework for research utilization applied to seven case studies. American Journal of Preventative Medicine, Vol.33, pp. 1S.

Poínhos, R., van der Lans, I.A., Rankin, A., Fischer, A.R., Bunting, B.P., Kuznesof, S., Stewart-Knox, B. and Frewer, L.J. (2014), Psychological determinants of consumer acceptance of personalised nutrition in 9 European countries. PLoS One, Vol.9, c110614.

Rankin, A., Kuznesof, S., Frewer, L.J., Orr, K., Davison, J., de Almeida, M.D. and Stewart-Knox, B. (2016), Public perceptions of personalised nutrition through the lens of Social Cognitive Theory. Journal of Health Psychology, 1-10. DOI 10.1177/1359105315624750.Ronteltap, A., van Trijp, J.C.M., Renes, R.J. and Frewer, L.J. (2007), Consumer acceptance of technology-based food innovations: lessons for the future of nutrigenomics. Appetite, Vol.49, pp.1-17.

Ronteltap, A., van Trijp, J.C.M. and Renes, R.J. (2008), Making nutrigenomics work Integrating expert stakeholder opinions and consumer preferences. Trends in Food Science and Technology, Vol.19, pp.390-398.

Silverman, D. (2013), Doing Qualitative Research: A Practical Handbook (4 ${ }^{\text {th }}$ Edition) Ch4, pp44-49. London: sage. 
Solas, M., Milagro, F.I., Martínez-Urbistondo, D., Ramirez, M.J. and Martínez, J.A. (2016), Precision obesity treatments including pharmacogenetic and nutrigenetic approaches. Trends in Pharmacological Science, Vol.37, pp.575-93.

Stewart-Knox, B.J., Bunting, B.P., Gilpin, S., Parr, H.J., Pinhão, S., Strain, J.J., de Almeida, M.D. and Gibney, M. (2009), Attitudes toward genetic testing and personalised nutrition in a representative sample of European consumers. British Journal of Nutrition, Vol.101, pp.982-9.

Stewart-Knox, B., Kuznesof, S., Robinson, J., Rankin, A., Orr, K., Duffy, M., Poínhos, R., de Almeida, M.D., Macready, A., Gallagher, C., Berezowska, A., Fischer, A.R., Navas-Carretero, S., Riemer, M., Traczyk, I., Gjelstad, I.M., Mavrogianni, C. and Frewer, L.J. (2013), Factors influencing European consumer uptake of personalised nutrition. Results of a qualitative analysis. Appetite, Vol.66, pp.6774.

Stewart-Knox, B.J., Markovina, J., Rankin, A., Bunting, B., Kusnezof, A., Fischer, A., Poínhos, R., Vaz de Almeida, M.D., Panzone, L., Gibney, M. and Frewer L. (2016), Making personalised nutrition the easy choice: policies to break down the barriers and reap the benefits. Food Policy, Vol.63, pp.134-144.

Sun, Y.V. and Hu, Y.J. (2016), Integrative analysis of multi-omics data for discovery and functional studies of complex human diseases. Advanced Genetics, Vol.93, pp.147-90.

Vaismoradi, M., Turunen, H. and Bondas, T. (2013), Content analysis and thematic analysis: Implications for conducting a qualitative descriptive study. Nursing and Health Science, Vol.15, pp.398-405. 
Whelan, K., McCarthy, S. and Pufulete, M. (2008), Genetics and diet-gene interactions: involvement, confidence and knowledge of dietitians. British Journal of Nutrition, Vol.99, pp.23-8.

Wisdom, J.P., Chor, K.H., Hoagwood, K.E. and Horwitz, S.M. (2014), Innovation adoption: a review of theories and constructs. Administration and Policy in Mental Health, Vol.41, pp.480-502.

Wright, O.R. (2014), Systematic review of knowledge, confidence and education in nutritional genomics for students and professionals in nutrition and dietetics. Journal of Human Nutrition and Dietetics, Vol.27, pp.298-307. 
Table 1: Profile of the participating Registered Dietitians (RD's)

\begin{tabular}{|c|c|}
\hline Total RD's & 12 \\
\hline Gender (female) & 12 \\
\hline $\begin{array}{l}\text { Years since graduation } \\
0-9 \text { years } \\
10-19 \text { years } \\
20-29 \text { years } \\
>30 \text { years }\end{array}$ & $\begin{array}{l}1 \\
6 \\
3 \\
2\end{array}$ \\
\hline $\begin{array}{l}\text { Level of education } \\
\qquad \text { BSc } \\
\text { Masters } \\
\text { PhD } \\
\text { Other qualifications } \\
\text { Food science } \\
\text { Sport science } \\
\text { Medical herbalism } \\
\text { Business and management } \\
\text { Clinical research } \\
\text { CPD Nutritional genomics }\end{array}$ & $\begin{array}{l}1 \\
1 \\
1 \\
2 \\
1 \\
12\end{array}$ \\
\hline $\begin{array}{l}\text { Job role/s } \\
\text { Lecturing/Private practice } \\
\text { Business/Private practice } \\
\text { Private practice only }\end{array}$ & $\begin{array}{l}4 \\
4 \\
4\end{array}$ \\
\hline $\begin{array}{c}\text { Country of residence } \\
\text { United Kingdom } \\
\text { Australia } \\
\text { South-Africa } \\
\text { Canada } \\
\text { Israel } \\
\text { Mexico }\end{array}$ & $\begin{array}{l}2 \text { (Pilot) } \\
3 \\
2 \\
3 \\
1 \\
3\end{array}$ \\
\hline
\end{tabular}


Figure 1: Profiles, perspectives, attitudes and experiences of early users, thematic analysis

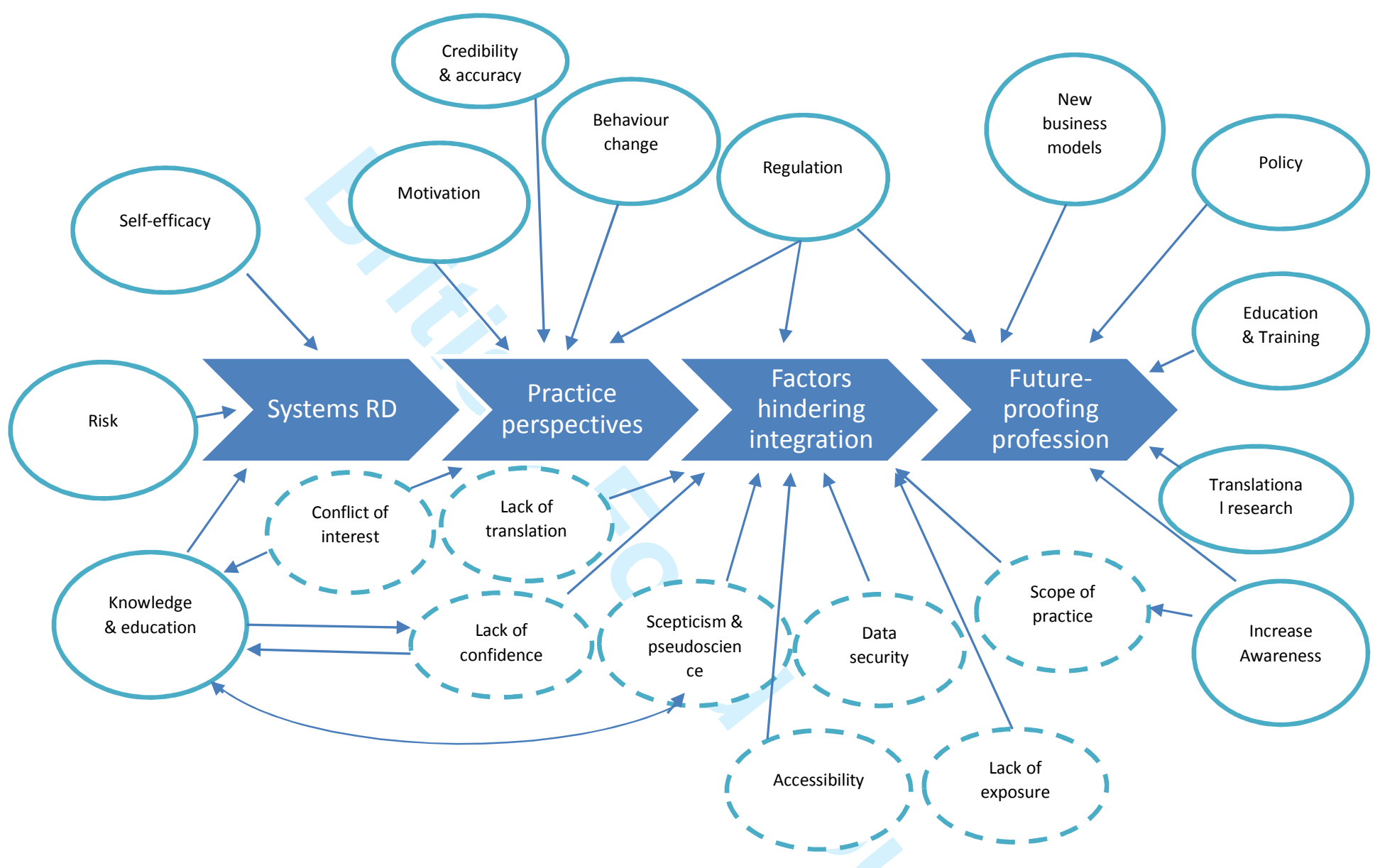

